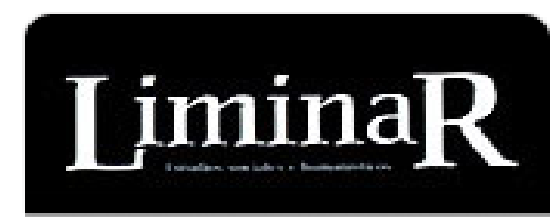

Ining
LiminaR. Estudios Sociales y Humanísticos

ISSN: $1665-8027$

liminar.cesmeca@unicach.mx

Centro de Estudios Superiores de México y

Centro América

México

Jasso Martínez, Ivy Jacaranda

Las demandas de las organizaciones purépechas y el movimiento indígena en Michoacán

LiminaR. Estudios Sociales y Humanísticos, vol. VIII, núm. 1, junio, 2010, pp. 64-79

Centro de Estudios Superiores de México y Centro América

San Cristóbal de las Casas, México

Disponible en: http://www.redalyc.org/articulo.oa?id=74516322005

- Cómo citar el artículo

- Número completo

- Más información del artículo

- Página de la revista en redalyc.org

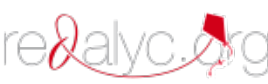

Sistema de Información Científica

Red de Revistas Científicas de América Latina, el Caribe, España y Portugal

Proyecto académico sin fines de lucro, desarrollado bajo la iniciativa de acceso abierto 


\title{
LAS DEMANDAS DE LAS ORGANIZACIONES PURÉPECHAS Y EL MOVIMIENTO INDÍGENA EN MiCHOACÁN
}

\author{
Ivy Jacaranda Jasso Martínez
}

Resumen: El presente texto tiene como objetivo hacer un análisis de las cuatro principales demandas de las organizaciones purépechas más reconocidas por su experiencia en Michoacán. Nos enfocamos en una perspectiva histórica que nos permite percibir cambios y variaciones en éstas, de acuerdo al contexto político y social del país. La lucha por el territorio, la autonomía, la remunicipalización y la representatividad política se expresarán en diferentes momentos y responderán a la existencia de condiciones propicias para la emergencia indígena.

Palabras clave: Demandas indígenas, purépechas, movimiento, autonomía, territorio, remunicipalización.

Enviado a dictamen: 23 de abril de 2010

Aprobación: 26 de mayo de 2010

Revisiones: 1

Ivy Jacaranda Jasso Martínez, doctora en Ciencias Sociales. Es profesora investigadora de tiempo completo de la Universidad de Guanajuato en el Departamento de Estudios Sociales, división de Ciencias Sociales y Humanidades, Campus León. Temas de especialización: movimientos indígenas, demandas y organizaciones indígenas de Michoacán y Oaxaca, identidades, derechos sociopolíticos de los pueblos indígenas, procesos de lucha y reivindicación étnica. Correo electrónico: ivyja@yahoo.com.
Abstract: This paper is center in a analysis of four from popular purepecha organizations' demands. From a historical perspective we perceive changes and variability in the demands, in relation with politic and social context in the country. The dispute for the territory, autonomy, remunicipalization and politic representation is presents in different moments and respond to the good conditions for the indigenous emergency.

Key words: Iindigenous demands, purepechas, movement, authonomy, territory, remunicipalization.

\section{Los antecedentes de las organizaciones indígenas en Michoacán}

L os orígenes de las agrupaciones y organizaciones indígenas en Michoacán se remontan distribución de tierras se dio en forma paulatina desde el pronunciamiento de la Constitución de 1917, aunque el reparto de tierras vivió su mayor auge durante la presidencia del general Lázaro Cárdenas del Río (1934-1940). A partir de esta administración el gobierno adoptó un sistema corporativista con un régimen de partido único. En él, los campesinos y ejidatarios fueron agrupados en la Confederación Nacional Campesina 
(CNC, creada en 1938) que pertenecía al partido de Estado (PNR y después PRI). Este sistema se acompañó del clientelismo como única forma de acceder a recursos y a la solución de litigios por tierras.

En la década de 1970, el sistema corporativista entró en crisis debido a su autoritarismo y a la concentración del poder en las cúpulas. El proceso de representación y control por las agrupaciones corporativas se desgastó, ya que a mediados de esta década ocurrió la subvaloración de los productos agrícolas, y la manipulación política de los campesinos a través de los votos se agudizó. Como respuesta a esta situación, a principios de los setenta, surgió el movimiento campesino.

En esta línea, la lucha en defensa de la tierra no es algo nuevo y se remonta a décadas pasadas, incluso la demanda de autonomía, anota Mallon (2003), la podemos rastrear hasta inicios del siglo XIX entre campesinos indígenas. Pero el contexto de formación del estado-nación mexicano permitirá que estas movilizaciones tengan eco como parte de las demandas que fortalecieron la lucha de la Revolución, y que por tanto aparezcan como válidas.

La zona norte y noroeste (Sinaloa, San Luis Potosí, Jalisco y Tamaulipas) concentró la mayoría de las movilizaciones debido a que el capital agropecuario entró en unafase expansiva que provocóla concentración de la tierra para la producción de oleaginosas y forrajes (Rubio, 1987:22). Los campesinos y jornaleros del campo se enfrentaron a la burguesía agrícola de punta. En esta etapa (1970-1976) las principales demandas fueron la dotación y recuperación de tierra, y la toma de tierras fue la principal forma de movilización.

En Michoacán, en 1971 se aprobó la ley federal de la Reforma Agraria. A partir de entonces las demandas agrarias de las comunidades purépechas cobraron ímpetu y el gobierno federal tendió a dar el fallo judicial a su favor (Yasumura, 2003: 656). Las políticas de explotación de los bosques originaron frentes de lucha y se formaron coaliciones intercomunitarias para la defensa de éstos. Se empezó a constituir un movimiento campesino en el que coincidieron luchadores sociales, líderes comunitarios, organizaciones independientes y autoridades comunitarias.

En 1976, las movilizaciones y sus efectos sobre la inversión de capital obligaron al Estado a realizar la expropiación de los Valles del Yaqui y Mayo en Sonora, y el Valle de Culiacán en Sinaloa (Rubio, 1987: 26). Esta estrategia, dirigida por el gobierno de Echeverría, pretendió frenar el movimiento a través de la concesión parcial a sus demandas.

Para estos años, la identificación como campesino tenía cabida como parte de las demandas incorporadas en la agenda del estado revolucionario. En este sentido, el contexto propició condiciones para su reconocimiento y la legitimidad de su lucha como ya mencioné. Estos movimientos sociales reactivaron los discursos revolucionarios y permitieron que el Estado se legitimara a través de algunas acciones (como las anteriormente enunciadas). Sin embargo, el gobierno federal también implementó estrategias de cooptación de grupos y líderes campesinos.

Durante esta administración se impulsó la creación del Consejo Nacional de Pueblos Indígenas (CNPI) ${ }^{1}$ y se amplió la cobertura del Instituto Nacional Indígena (INI). El CNPI fue incluido en la CNC, pero años más tarde se separó de ésta al oponerse a la política agrícola que apoyaba. También intentó obtener espacios autónomos de decisión, pero el Estado intentó controlar la organización de los indios a través la creación de los 56 Consejos Supremos Indígenas (1975). Las invasiones campesinas se diseminaron en el norte, pero en la región centro-sur (Veracruz, México, Oaxaca, Chiapas, Hidalgo y Puebla) cobraron ímpetu (Rubio, 1987).

El presidente José López Portillo aplicó una política anticampesinista (conclusión del agrarismo oficial, y una política de fin de reparto) y sometió al campesinado mediante la represión; además, tipificó la toma de tierras como delito del fuero común (Rubio, 1987: 27). Estas medidas ocasionaron un repliegue generalizado del movimiento campesino, y en los años 1977 y 1978 
se fortalecieron las organizaciones oficiales. En 1979 el movimiento se recuperó y se creó la Coordinadora Nacional Plan de Ayala (CNPA) ${ }^{2}$, que desde entonces coordinó al movimiento nacional. La recuperación de tierras continuó siendo la principal demanda, especialmente los campesinos indígenas enfrentaron el ataque de ganaderos y taladores en sus tierras comunales.

En Michoacán, la organización que aglutinó las principales demandas fue la Unión de Comuneros Emiliano Zapata (UCEZ). Ésta surgió en noviembre de 1979 en la comunidad de Tingambato, y su objetivo general fue constituir una organización que defendiera los intereses de los que la formasen y de los demás campesinos (Máximo, 2003: 581). Esta organización estaba conformada por campesinos mestizos e indígenas, y la articulación a discursos y demandas regionales y nacionales oscurecía las diferencias étnicas en su interior. No obstante lo anterior, la UCEZ se fortaleció a partir de la lucha, en el mismo año, de los comuneros indígenas de Santa Fe de la Laguna contra los ganaderos mestizos de Quiroga. La lucha de esta comunidad inició con demandas agrarias y concluyó con reivindicaciones étnicas acompañadas de la construcción de símbolos (bandera y lema purépecha) que legitimaron la lucha, y que más tarde se convirtieron en referentes para todo el pueblo purépecha. A partir de este momento, los pobladores de Santa Fe empezaron a conformar un conjunto de demandas, discursos y símbolos que hacía referencia a su identidad étnica.

Se puede argumentar que esta disputa alertó al gobierno estatal del discurso con tintes etnicistas, a lo que se sumó la inicial aplicación de políticas indigenistas de "participación" como producto de las críticas hechas a las anteriores políticas indigenistas de tinte integracionista. Esto provocó que, como estrategia utilizada para frenar el avance del movimiento campesino de identificación purépecha en Michoacán, se fortaleciera el recién creado Consejo Supremo Purépecha y se fomentará la constitución del Frente
Juvenil Purépecha, estas instancias fueron instrumentos para la manipulación y control del naciente movimiento indígena. Sin embargo, también funcionaron como espacios de encuentro e intercambio entre algunos de los futuros líderes y dirigentes indígenas de organizaciones independientes.

Como mencioné, las críticas al indigenismo integracionista provocaron que el gobierno federal, a cargo de Miguel de la Madrid (1982-1988), lanzara una política indigenista que recurrió a la idea de etnodesarrollo y estimuló proyectos económicos planteando a las organizaciones el desarrollo autogestivo (Sarmiento, 1996: 369). Estas políticas promovieron la creación de organizaciones indígenas y favorecieron el desarrollo de discursos étnicos que marcaban diferencias con los campesinos mestizos.

Con estos antecedentes, las demandas enarboladas por los campesinos en defensa de sus tierras serán reelaboradas con otros significados aunque por los mismos agentes, pero que presentarán a sí mismos con su diferencia cultural como definitoria de su ser.

\section{Las organizaciones purépechas y sus demandas en Michoacán}

En 1981, en Cheranástico, Michoacán se realizó el 2º Encuentro de Organizaciones Indígenas Independientes de México, Centroamérica y el Caribe. Con éste se buscó fortalecer el movimiento campesino independiente en Michoacán, y a pesar de que el discurso clasista y marxista tenía gran peso la diferencia cultural se asumió de manera clara. Surgieron agrupaciones purépechas como la Asociación de Profesionistas de Zacán, la Federación de Profesionistas Purépechas, el Comité de Pueblos Purépechas por los Cinco Puntos, la organización Camino del Pueblo (Xanaru Ireteri); y se fortalecieron organizaciones como la UCEZ, un sector de la Alianza Nacional de Profesionales Indígenas Bilingües (ANPIBAC) y el Movimiento Indígena Revolucionario (MIR) (Máximo, 2003: 582). 
Estas organizaciones surgieron en un contexto de relativa apertura política, ya que en otros países de América Latina las agrupaciones de indígenas empezaron a ser escuchadas sin intermediarios (mestizos) en sus demandas de reconocimiento y a favor de mejores condiciones de vida. Es posible que para entonces aún no hubiera una separación tan marcada entre organizaciones mestizas campesinas y organizaciones indígenas igualmente campesinas.

En esta década el movimiento campesino se volvió más defensivo, pues intentaba mantener los logros ganados. En 1983, en Michoacán se registraron 17 actos relacionados con la lucha agraria: 1 asamblea y encuentro, 1 bloqueo, 2 invasiones de tierra, 8 marchas y mítines, 1 plantón, 4 tomas de oficina, en total 17, de los cuales la UCEZ realizó 2 marchas y mítines, y l plantón (Encinas y Rascón, 1987: 50-51). También hubo actos de represión en esta entidad: 1 asesinato, 1 desalojo, 1 despojo, 103 presos, 1 represión general y ll secuestrados o desaparecidos (Encinas y Rascón, 1987).

Relacionado con esta situación, el CNPI se desintegró en organizaciones indígenas independientes debido a las presiones del gobierno y éste fomentó la creación del Consejo Indígena Permanente (CIP) en alianza con la CNC (Sarmiento, 2001: 79). A pesar de que parece un escenario adverso, aparecieron organizaciones indígenas independientes, relacionadas con organizaciones no gubernamentales.

El gobierno de Miguel de la Madrid inició el desmantelamiento del aparato estatal de bienestar. Su periodo se caracterizó por una inflación incontrolable, un crecimiento nulo y la caída de salarios reales; y los subsidios a la producción agrícola y el consumo popular empezaron a desaparecer (Anaya, 2006: 25). El partido de estado (PRI) fue cuestionado y en su interior existían pugnas. Se formó un ala disidente, la "Corriente democrática" dirigida por Cuauhtémoc Cárdenas y Porfirio Muñoz Ledo. Éstos demandaron "la democratización del proceso de selección del candidato presidencial" (Anaya, 2006: 28), y tiempo después abandonaron el partido y formaron el Frente Democrático Nacional (FDN). Cuauhtémoc Cárdenas (hijo del general Lázaro Cárdenas) fue postulado como candidato presidencial y atrajo el apoyo de la izquierda, de partidos de oposición y de organizaciones populares.

Las elecciones de 1988 fueron las más cuestionadas de la historia. El candidato del PRI, Carlos Salinas de Gortari, que compitió contra Cuauhtémoc Cárdenas, ganó en medio de denuncias de la implementación de un gigantesco fraude electoral. Esto incrementó las movilizaciones de organizaciones independientes políticas, campesinas, obreras, sindicales, entre otras. En Michoacán, la política electoral cobró mayor importancia y actividad; algunos miembros de organizaciones independientes indígenas apoyaron a Cuauhtémoc Cárdenas y se integraron al FDN, y posteriormente al PRD. Desde entonces existe un fuerte apoyo a este partido entre las poblaciones indígenas de la entidad. ${ }^{3}$

En 1991 se convocó a un primer Encuentro de Comunidades Indígenas de Michoacán en la localidad de Cherán. Con este acto seinició una etapa de organización y lucha por los intereses de las comunidades. Se constituyó el Frente Independiente de Comunidades Indígenas de Michoacán (FICIM) (Máximo, 2003: 584) y el Frente Independiente de Pueblos Indios (FIPI- Michoacán). Estas dos organizaciones trataron de ser más incluyentes y pusieron en primer lugar su diferencia cultural (como indígenas) separándose con esto del movimiento campesino. Ambas son el punto de despegue del movimiento indígena en la entidad.

En este momento se puede percibir una clara definición y adscripción indígena, recordemos que para esos años diversos grupos y organizaciones étnicas en el país ya estaban presentes en las arenas locales. Cabe aclarar que estas agrupaciones no representaban al total de la población indígena en sus regiones, ni siquiera lo hacen en la actualidad. Sino que se trata de un proceso de continua comunicación, discusión y reflexión que pone en el centro del debate cuáles son las 
demandas prioritarias, las formas de alcanzarlas y las maneras de solucionar las necesidades enunciadas. Lo anterior implica que hay población que considera que la forma más fácil y menos problemática para mejorar sus condiciones de vida es apegarse a las normas del estado, en contraposición con lo que las organizaciones independientes pretendieron en el inicio, como fue denunciar la marginación experimentada con conocimiento de causa del estado y confrontarlo.

Durante el gobierno de Carlos Salinas de Gortari (1988-1994) se anuncio una política de reconocimiento, a la vez que se concretizó el desmantelamiento del estado de bienestar asestando duros golpes a la política campesina. Dos reformas a la Constitución federal marcan de forma importante esta época. El 28 de enero de 1992 el Diario Oficial de la Federación publicó una reforma a la Constitución, un primer párrafo para ser sumado al artículo 4o de la Constitución mexicana (la "Nación mexicana tiene una composición pluricultural sustentada originalmente en sus pueblos indígenas"). Esta reforma - a diferencia del Convenio 169 de la OITno confirió derechos políticos o socioeconómicos a los pueblos indígenas, sino que reflejó las responsabilidades mínimas del Estado desde una óptica neoliberal.

Al mismo tiempo, la política dirigida al campo buscó adecuar el programa agrícola con los lineamientos del Banco Mundial, ya que éste condicionó el desembolso de nuevos fondos a cuenta de un ajuste estructural radical para liberalizar el mercado rural y quitar subsidios a productos agrícolas (Paz, 2005: 354). La reestructuración rural inició con la reforma al artículo 27 constitucional en 1992. Con ésta se puso fin a la posibilidad de redistribución de la tierra y representa un ataque ideológico contra la tenencia comunal. Además, se implementó el programa nacional de Solidaridad (PRONASOL) para paliar la pobreza intensificada por los recortes en el gasto público de la nueva estrategia económica.

Los efectos de la reforma al artículo 27 de la Constitución causaron alarma entre la población indígena michoacana. Las comunidades y sus autoridades se pronunciaron en contra. El Decreto de la nación purépecha (5 de diciembre de 1991), promovido por el FICIM y firmado por un gran número de comunidades indígenas, rechazo la reforma al artículo 27 y demandó mayores recursos para elevar la productividad en el campo (Com. Indígenas de Michoacán, 1995: 166). Este pronunciamiento reafirma el carácter agrarista de las luchas indígenas en la entidad. ${ }^{4}$ La posición con respeto al uso, manejo y cuidado de la tierra y sus recursos tienen implicaciones culturales para la existencia de éstos, ya que la forma de posesión (propiedad colectiva de la tierra) constituye su base unificadora.

La presión provocada con el pronunciamiento de tal oposición influyó en la conformación de un contexto de negociación. A lo que se sumaron los eventos alusivos a la conmemoración del 12 de octubre en 1992. En la capital del estado, Morelia, organizaciones y comunidades indígenas marcharon por el centro de la ciudad y culminaron con el derrumbamiento de la estatua del virrey Antonio de Mendoza, erigida meses antes por el ayuntamiento moreliano (Ramírez, 2005: 5). Este hecho mostró el descontento y la falta de una política adecuada para las poblaciones indígenas de Michoacán y la nación.

Como es conocido, el levantamiento del Ejército Zapatista de Liberación Nacional (EZLN) en el estado sureño de Chiapas por indígenas tzetzales, tojolabales, tzotziles el primero de enero de 1994, misma fecha en que entró en vigor el Tratado de Libre Comercio con EU y Canadá (conocido como TLC o ALCA), catapultó las dinámicas indígenas regionales, y a partir de entonces las organizaciones indígenas se vieron como parte de una misma lucha.

Como se observa, la identidad de campesino, que anteriormente había resultado eficaz para legitimar la lucha de los movimientos sociales, entró en una etapa de crisis y resurgirá años más tarde aunque sin la fuerza anterior. En cambio, se presenta un contexto propicio para la manifestación y reconocimiento de identidades 
étnicas, y que como veremos más adelante continúan vigentes no sin conflictos.

En Michoacán, como parte de las discusiones hechas en el FICIM, en ese año surgió la Organización Nación Purépecha (ONP). Ésta emitió la Carta de principios de la nacionalidad p'urhépecha de Michoacán, México: Ireta P'orhécheri-juchari Uinapekua con lo cual inició otra etapa de organización de los purépecha. Aunque el movimiento campesino se debilitó no desapareció. Pero es el movimiento indígena el que recoge las demandas agrarias al adquirir mayor importancia y volverse centro de atención nacional.

La lucha por la tierra reapareció entonces en las demandas del movimiento indígena y se reforzó la defensa de la propiedad comunal como característica de la mayoría de las poblaciones indígenas en el país. En esta línea, la ONP, junto con otros representantes y grupos purépechas, declaran propiedad comunal todos los territorios que en forma ancestral han venido utilizando las comunidades del pueblo purépecha para la realización de sus actividades sociales, económicas y religiosas (ONP, s/f a; Representantes y Autoridades Tradicionales, 2001; ONP, 2004). Esto se acompaña de nociones ambientalistas acerca de la conservación y protección de los recursos naturales, y la presentación de una relación armónica entre indígenas y naturaleza: "Nosotros, como Pueblo Purépecha, construimos durante siglos una rica cultura en la que hemos aprendido y entendido que, junto con la naturaleza, formamos un conjunto integral y armonioso" (Representantes y autoridades tradicionales, 2001: 152).

La presentación de una relación armónica con la naturaleza se inscribe en un contexto internacional en el que esta misma relación (conjunto integral) se ha convertido en un recurso a través del cual se puede acceder a apoyos de diversa índole. Pero, es necesario tomar con cuidado esta apreciación, ya que en la región purépecha no existe un manejo adecuado en la explotación de los bosques (por lo menos en la Cañada y la Meseta), y la contaminación de ríos y arroyos es un serio problema.

Máiz (2004) argumenta que hay un cambio en el discurso, en la primera mitad de la década de 1990, de uno orientado a la mera demanda de tierra como parte del sector campesino — en la década de 1970-, a otro en que se ponen por delante los aspectos étnicos (respeto a la diferencia), y la combinación de peticiones de orden económico y material. En el cuadernillo Juchari Juramukua (Nuestra Autonomía), publicado por la ONP en 1997, los purépechas se presentan como dueños de sus territorios (incluyendo bosques, aguas y demás recursos naturales) desde antes de la llegada de los españoles y apelan a su derecho al territorio amparados en el Convenio 169 de la OIT. ${ }^{5}$ Esta demanda también incluye la disposición y aprovechamiento de los recursos existentes en éstos (ONP, 2001: 7).

En 1998 algunos de los líderes de la ONP deciden separarse por diferencias en las estrategias de lucha y la distribución de recursos. Se crea entonces la organización Nación Purépecha Zapatista, más cercana a los postulados del EZLN. Esta fractura indica las diferencias y enfrentamientos al interior de la organización y la gran influencia de los líderes, ya que fue una decisión que se tomó en la cúpula, y en la cual las bases no intervinieron y sólo debieron elegir cuál de los líderes representaba mejor sus demandas. Esto también muestra las divisiones que existen en el movimiento indígena en la entidad, ya que a partir de esta división se promovieron o rompieron alianzas con otras organizaciones nacionales, internacionales, de indígenas y no indígenas.

La organización Nación Purépecha Zapatista (NPZ) se apoya en diferentes artículos (del 13 al 19) del Convenio 169 de la OIT para respaldar su derecho al reconocimiento de su territorio. Esta visión puede haber sido apropiada por las organizaciones a partir de los textos y ensayos académicos que empezaron a fijar su atención en la eficacia de los sistemas productivos indígenas. Lo que también implica la defensa de su capacidad para 
decidir la forma de desarrollo que incluya el control y protección de sus recursos naturales. A lo que se suman los conflictos agrarios, que para la NPZ y ONP se generaron como una estrategia (implementada por el gobierno) de división al interior del pueblo purépecha.

Las poblaciones y organizaciones indígenas también inscriben entre sus demandas servicios básicos, infraestructura, y participación política en los espacios de decisión. Estas demandas tienen como finalidad mejorar su nivel de bienestar, que se ha caracterizado (como la población rural en general) por presentar grados de pobreza y marginación considerables. En esta vertiente, las organizaciones han creado un proyecto autonómico que les permita mantener el control sobre su territorio.

La idea y el proyecto de territorialidad étnica (como sustento material y simbólico de cada grupo) se ligan a la formulación de una política y de una práctica autónoma en todo lo que atañe a la vida en el interior del grupo (Stavenhagen, 1988: 149). La relación entre territorio y autonomía se vuelve indisoluble.

En el Decreto de la Nación Purépecha, fechado el 5 de diciembre de 1991, las comunidades indígenas de Michoacán no hacen referencia a la autonomía o la libre determinación, y el autonombrarse como pueblo tampoco aparece; en cambio, utilizan el apelativo de Nación. (Comunidades Indígenas de Michoacán, 1995: 165). Ya para el año de 1997, el cuadernillo Juchari Juramukua (Nuestra Autonomía) tuvo como principal objetivo explicar lo que se entiende por autonomía (regional), sus implicaciones y retos para lograrla. En él se define a la autonomía como:

a. Una de las formas de ejercer la libre determinación;

b. Una delegación de atribuciones y competencias mutuamente acordadas entre sujetos políticos (gobierno y pueblos indios);

c. la capacidad de decidir sobre el destino propio, incluidas cuestiones y acciones inmediatas y diarias; d. Poder decidir sus propios proyectos de desarrollo, tipo de gobierno, formas de participación en los órganos de jurisdicción del Estado, el destino y condiciones de explotación;

e. La facultad para gobernarse con sus propias leyes (Victoriano, 1997: 11-14).

En documentos más recientes (con madurez en la discusión de las demandas étnicas) la autonomía se convierte en "un proyecto de pervivencia para el pueblo purépecha y para los pueblos indígenas de México" (ONP, 2001). La demanda se generaliza y todos los purépechas e indígenas se vuelven los agentes del cambio. Aunque, en la práctica, la discusión en torno a este tema se centra en unos cuantos individuos.

La ONP considera la autonomía como una alternativa para "satisfacer las necesidades de una vida mejor e integral, y para oponernos a un sistema de explotación de nuestros recursos naturales que nos han sumido a la más profunda pobreza y a la mayor degradación económica, cultural y social" (Victoriano, 1997: 1). Esta organización reconoce la existencia de tres formas de autonomía: comunal, municipal y regional; pero, en específico, se inclina por la autonomía regional. Uno de sus coordinadores, Norberto, afirma que la autonomía comunal es necesaria para la regional y que esta última incluye a la comunal; que ambos planteamientos están conectados y se integran (2005). La preferencia por la autonomía regional se debe a "las características geográficas en que vivimos e implica el ejercicio de un elemental derecho de cualquier tipo de colectividad, la autoadministración política, territorial, cultural y económica" (ONP, 2001: 10). La autonomía regional de la ONP se acerca a la postura de la Asamblea Nacional Indígena Plural por la Autonomía (ANIPA) de la cual forman parte, pero que en años recientes se ha distanciado. ${ }^{6}$ A diferencia de esta organización, el Congreso Nacional Indígena (órgano que surgió a instancia del EZLN) se inclina por la autonomía comunal. 
La ANIPA ha optado por propiciar cambios desde la estructura del Estado, es decir, algunos de sus dirigentes han aceptado cargos en la administración gubernamental para propiciar cambios favorables a los pueblos indígenas desde allí. Sin embargo, hay serias críticas a esta modalidad. Nahmad considera que instaurar una autonomía regional, como algo ajeno a la vida comunitaria, supone dificultades tales como la demarcación de la participación política de los pueblos indígenas y los mestizos, y la posibilidad de caciquismos regionales cuando uno o unos pocos individuos lleguen a detentar el poder en representación de toda la región (Nahmad, 2003: 356 357). Hay que precisar que aunque hay una evolución en las demandas, las formas que se proponen como alternativas pueden ser extrañas a las dinámicas comunitarias, y por tanto, propiciar más desigualdades y conflictos.

$\mathrm{Al}$ preguntar por el rubro de la autonomía y las implicaciones que ésta tendría en comunidades de la Cañada de los Once Pueblos (en el estado de Michoacán) algunos integrantes afirmaron desconocer ese punto o sólo haber escuchado la palabra, pero no sabían su contenido. El desconocimiento que algunos purépechas tienen con respecto a estas discusiones es manejado por el gobierno y críticos a esta alternativa como la imposición, por un grupo reducido, de un proyecto ajeno. Esto nos muestra nuevamente la diversidad de opiniones y discursos al interior del movimiento, y la construcción desde una elite (líderes purépechas) de discursos vinculados con los argumentos nacionales e internacionales y poco aterrizados en la discusión comunitaria o local. En este sentido, se corre el riesgo de que a articulación que se logra a partir de la producción de discursos consecuentes con las demandas del movimiento indígena nacional no produzcan la legitimidad necesaria en el ámbito local.

Esta adecuación entre demandas locales, regionales y nacionales no ha sido suficientemente estudiada, los movimientos indígenas que tratan de volverse más amplios han aglutinado las demandas locales en derechos de corte nacional, que resultan ajenos a los indígenas que no están muy involucrados en las organizaciones y la arena política. Al mismo tiempo tratan de crear versiones oficiales acerca de las demandas indígenas y de la comunidad indígena, lo que propicia que se pierda especificidad y que la identificación no sea automática; sin embargo, esta estrategia ha contribuido a dar proyección externa al movimiento indígena y sus líderes.

Regresando a la discusión acerca de la autonomía, lo que se requiere para que los sujetos autonómicos queden complacidos y el arreglo sea el fundamento de una solución firme y duradera, afirma Díaz-Polanco, es que la autonomía implique un empoderamiento de los sujetos, que las colectividades beneficiadas con este régimen asuman plenamente los derechos mínimos que supongan y adquieran el poder imprescindible para que sus miembros se conviertan en verdaderos ciudadanos (Díaz-Polanco, 2001: 16). Aunque habría que agregar que las demandas y las formas de solución deben surgir desde abajo, desde las comunidades que las experimentan. De otra forma se podría nuevamente caer en el juego de proporcionar a los indígenas la ayuda y los medios que otros consideran necesarios.

En acuerdo con el discurso oficial del movimiento indígena nacional, en la mayoría de sus documentos, la ONP aclara que su concepción de autonomía no significa separación del Estado mexicano:

- No consiste en una independencia total ni una autonomía externa (Victoriano, 1997: 8).

- No implica separatismo de nuestro México, implica la convivencia social de la diversidad, pero en igualdad de condiciones (ONP, 2000: 1).

- No es ir en contra de la unidad nacional, ni pretender la independencia o separación (ONP, 2001: 8). 
Esto muestra su interés en formar parte del país y de que mantienen la pertenencia a una comunidad más amplia, México. Esto acallaría las preocupaciones acerca de separatismos y peligros para la unidad nacional. Aunque cabe recordar que el nombrarse como Nación puede tener otro tipo de implicaciones, y que posiblemente han sido olvidadas por no coincidir con el discurso ahora legítimo.

Una vía que están proponiendo estas organizaciones e incluso las comunidades para lograr la autonomía es el reconocimiento del Gobierno Federal y del Gobierno Estatal de las comunidades como "entidades públicas que forman parte de la estructura del Estado Mexicano y al Pueblo Purhépecha como sujeto de Derecho Público" (Representantes y autoridades tradicionales del pueblo purépecha, 2001: 48). Esta demanda también es tratada por la vía de la remunicipalización y la creación de "municipios indígenas", así como la redistritación electoral. Ninguna de las tres organizaciones indígenas (ONP, NPZ, UCEZ) han presentado dichas propuestas ante el Congreso local. Ramírez (2005) identifica una tipología en las propuestas de remunicipalización en Michoacán ${ }^{7}$ y apunta que entre los municipios mencionados para este proceso están: Chilchota (Carapan, Ichán), Charapan (Ocumicho), Nahuátzen (Arantepacua), Santiago Tangamandapio (Tarecuato), Paracho (Nurío), Cherán (Tanaco), Quiroga (Santa Fe de la Laguna, San Jerónimo Purhéchecuaro), Coeneo (Zipiajo, Santiago Azajo), Los Reyes (Pamatácuaro, Zicuicho), Pátzcuaro (Cuanajo), Tingambato (San Francisco Pichátaro), Uruapan (Capácuaro, San Lorenzo, Caltzontzin), Tangancícuaro (Patamban), Zacapú (Tiríndaro) (Ramírez, 2005: 14-15).

Esta demanda es quizás la que goza de mayor conocimiento y simpatía entre indígenas que no pertenecen a las organizaciones del movimiento, ya que no implican un enfrentamiento directo con el gobierno, sino que puede ser un recurso legal que está estipulado en la Constitución (creación de municipios). Aunque no por esto es menos conflictiva; la demanda de remunicipalización ha creado disputas al interior de los municipios y entre comunidades, el problema radica en quién fungiría como la cabecera municipal y cómo se hará el reordenamiento al interior de estos nuevos municipios. A pesar de que en los casos de Tarecuato y Tiríndaro se tenían mayores posibilidades de lograr su aprobación por la legislatura del Estado, no se logró por falta de consenso entre las fracciones partidistas.

Estas alternativas son vistas como formas de acceder a los órganos de representación popular y lograr la autogestión y el acceso a recursos. Ambas vías implican el reconocimiento del Estado.

La ONP ha propugnado la no intervención de los partidos políticos en la solución de sus problemas colectivos, lo cual se apoya en su derecho a decidir su forma de gobierno y sus maneras de organización, así como sus sistemas normativos internos. Sin embargo, en los documentos consultados no hay alguna oposición explícita a las elecciones de autoridades por el sistema de partidos políticos. Hay que mencionar que las bases son perredistas y algunos de los coordinadores han postulado para cargos públicos desde el PRD (partido a través del cual han obtenido cargos de autoridad municipal). Quedarían pendientes las negociaciones que éstos hacen con las cúpulas dirigentes de los partidos, por lo menos en el ámbito regional.

En esta línea, una aspiración de la ONP es llegar a ser una fuerza política que pueda organizar la solución de los problemas colectivos (ONP, 2004). Cabría entonces preguntarse qué tipo de fuerza política, tal vez un partido político, una asociación política o una corriente dentro de algún partido. Esta aspiración no ha sido lo suficientemente consensuada entre las bases ya que la mayoría simpatiza con el PRD. En este sentido, sigue presente a diversidad del movimiento y la adecuación de su discurso a los momentos, los actores y las condiciones del contexto.

Específicamente la participación o no en partidos políticos es una cuestión delicada, ya que mientras el EZLN y el movimiento indígena nacional manifiestan 
su repudio a éstos, en Michoacán, los purépechas se sienten identificados principalmente con el PRD y su participación ha sido decisiva en momentos claves de la historia de la entidad. Incluso, un llamado a la no participación en los partidos políticos podría ser contraproducente para el movimiento indígena michoacano, a pesar de que se conocen los manejos y la corrupción que impera en éstos. Es decir, las prácticas políticas entre la población indígena han estado en constante interacción e influencia con los procesos electorales en sus diferentes niveles.

\section{Nuevas propuestas, iguales demandas}

La demanda de autonomía regional indica transformaciones tanto en la emergencia indígena en México, como en los términos en que se expresan las organizaciones para legitimar su lucha. Nuevos contenidos son incorporados a la lucha indígena y en la evolución de las demandas se advierte el paso de un discurso comunalista a uno etnicista, y finalmente regionalista. El discurso de las organizaciones aquí referidas inició con la defensa de la tierra y la propiedad comunal, para después acentuar su carácter étnico, y en los documentos recientes la demanda de autonomía regional se complementa con las anteriores exigencias. Además, en los dos últimos años se prepara un borrador de reforma a la Constitución del Estado de Michoacán para que se reconozcan a los pueblos indígenas en la entidad y que dé cabida a la ley de derechos y cultura de los pueblos indígenas.

Las organizaciones indígenas enunciadas anteriormente han participado (principalmente los coordinadores) en la propuesta de ley indígena en Michoacán desde 2001 a la fecha. Asistieron a los foros regionales para que sus opiniones fueran tomadas en cuenta; así mismo, discutieron y reflexionaron en dichos espacios. Algunos líderes y agrupaciones se han enfrentado a la disyuntiva de participar en el proceso para la creación de una ley en el estado o no participar y ser consecuentes con el EZLN en lo que respecta a una primera reforma a la reforma antes de cualquier otra ley referente a los pueblos indígenas. Esto podría implicar una separación del movimiento indígena nacional, sin embargo, estas organizaciones han podido trabajar en ambos frentes.

Una actividad significativa con respecto a la propuesta fue la irrupción que hicieron algunos de sus integrantes para detener su presentación ante el Congreso local en Morelia, alegaron no conocerla ni haber participado en su creación en 2004. Ya que a pesar de que acudieron y participaron en los foros y mesas de discusión, desconocían la propuesta que sería presentada en el congreso local.

En esta línea, y una vez que Lázaro Cárdenas Batel dejó la gobernatura del estado, las organizaciones, líderes y grupos indígenas de Michoacán han vuelto a plantear sus demandas. Con el actual gobernador, maestro Leonel Godoy Rangel, se creó la Secretaría de Pueblos Indígenas (SPI) que sustituyó a la anterior Coordinación Interinstitucional para la Atención de los Pueblos Indígenas de Michoacán (CIAPI). En esta instancia se reunió a los coordinadores y dirigentes de las organizaciones indígenas con más presencia en el estado, y de las cuales hemos tratado aquí. Esta estrategia de cooptación ha provocado un impasse en el movimiento indígena michoacano, sin embargo, desde este espacio se propugna la reforma constitucional.

Desde el 2008 se tiene una versión final del borrador (Propuesta de reforma constitucional para el reconocimiento de los derechos de los pueblos indígenas de Michoacán, 2008) para ser discutido con los partidos políticos y después ser presentado en el congreso local. Las cuatro principales demandas que se han venido discutiendo tienen en este borrador un aspecto central e inician con el reconocimiento de la existencia de pueblos indígenas en el estado de Michoacán:

El Estado de Michoacán de Ocampo tiene una composición pluriétnica, pluricultural y plurilingüe 
sustentada originalmente en sus pueblos indígenas constituidos por sus comunidades y personas. Esta Constitución reconoce la existencia histórica y actual, en su territorio, de los pueblos indígenas Purhépecha, Nahua, Hñahñú (Otomí), Jñatjo (Mazahua), Pirindas y Matlatzincas, considerados como los descendientes de las poblaciones que habitaban el territorio del actual Estado de Michoacán en la época de la conquista y la colonización, que preservan todas sus propias instituciones económicas, sociales, culturales, políticas y territoriales o parte de ellas (Comisión plural, 2008).

Además, se especifica el criterio de autoidentificación como referente fundamental para la aplicación de las disposiciones legales contenidas en la Constitución. Considero que uno de los cuestionamientos a este reconocimiento, y que se prevé se especificará en la ley reglamentaria, son los mecanismos para la identificación y delimitación de los pueblos indígenas, municipios, comunidades y personas indígenas. Se apunta que los pueblos indígenas deberán coadyuvar a este proceso de identificación y delimitación y que se tomarán en cuenta criterios históricos, económicos, sociales, lingüísticos, culturales, territoriales, jurídicos y jurisdiccionales. No se nombra a la institución, secretaría o departamento que así lo haga, y aunque se enuncia el criterio de autoidentificación parece que no basta con este.

El derecho a la libre autodeterminación de los pueblos indígenas en el estado de Michoacán es tratado de la siguiente forma:

El estado de Michoacán, en el marco jurídico nacional e internacional, reconoce el derecho a la libre determinación de sus pueblos indígenas, que se expresa en el ejercicio de su autonomía en los niveles comunal, municipal y regional, en los siguientes ámbitos y competencias (Comisión plural, 2008).
Se enuncian las competencias en que se practicará la autonomía y resultan bastante acertados sus ámbitos, aunque faltaría ser más específicos en la normatividad correspondiente. Entre uno de los derechos que hemos analizado en este texto, citan el derecho de los pueblos indígenas a "poseer, controlar y desarrollar las tierras y territorios que históricamente ocupan en los términos y modalidades establecidas en la Constitución Federal y demás leyes en la materia, así como a conservar y mejorar su hábitat y, además, gozar de la reivindicación de las tierras y territorios de dichos pueblos que de hecho y por derecho les corresponden" (Comisión plural, 2008). Así mismo, anulan toda acción de compra-venta en perjuicio de las tierras y territorios de los pueblos indígenas. El territorio es entonces definido como un derecho histórico de los pueblos indígenas y aclaran que tienen el control sobre éste. Sin embargo, faltaría enunciar, como en otros documentos lo hacen, el derecho al control y disfrute de los recursos naturales que poseen sus territorios, ya que la enunciación a "conservar y mejorar el hábitat" es aún débil.

En lo que respecta a la creación de municipios indígenas dicho borrador aclara en el artículo 44, como parte de las facultades del Congreso, la creación de municipios para los pueblos indígenas con la particularidad de que funcionen y se administren de acuerdo a sus sistemas normativos y de organización, conforme a las siguientes bases:

a. La solicitud de erección debe ser hecha por las autoridades formales de una o varias comunidades integrantes de un pueblo indígena reconocido por el Estado, en cumplimiento del mandato expreso de la asamblea o asambleas comunales correspondientes, respaldada por un grupo de ciudadanos en número no menor de mil doscientos y con residencia en la comunidad de cuando menos tres años.

b. La fracción territorial que haya de constituirse en nuevo municipio indígena deberá corresponder 
a la que ocupan las comunidades solicitantes y contar con una población no menor de ocho mil habitantes;

c. El proceso de elección de los integrantes del $\mathrm{H}$. Ayuntamiento en los municipios indígenas, se hará conforme a sus sistemas normativos propios (Comisión plural, 2008).

Las diferencias con la creación de municipios no indígenas se refieren a la solicitud en el número de ciudadanos, específicamente no menor de mil y con residencia en la localidad de tres años cuando menos, es decir, menor que el solicitado para municipios para poblaciones indígenas y en éste último la solicitud será hecha por las autoridades formales de una o varias comunidades. El número de población para municipios no indígenas será no menor de 10 mil habitantes y la comprobación de que dicha fracción tiene los elementos necesarios para su existencia económica y administrativa, se elimina para municipios indígenas, así como la opinión del ayuntamiento o ayuntamientos del municipio o de los municipios de cuyo territorio pretenda formarse la nueva circunscripción municipal, así como la opinión del gobernador del estado desaparece. Además, se reconoce el derecho de "libre asociación entre comunidades, municipios indígenas y no indígenas de la entidad" con el fin de coordinar acciones y aspiraciones como pueblos indígenas. A lo que se suma la figura de regidor indígena en los municipios donde exista esta población y que no alcance la categoría de municipio indígena.

Finalmente, y una parte que fue ampliamente discutida por el grupo que participó en la elaboración del borrador (incluida la autora de este texto) es la demanda de representatividad. Existían dos propuestas: crear distritos indígenas para que de allí salieran representantes de estas poblaciones o crear una cota en el congreso local preestablecida para las poblaciones indígenas. En el borrador quedo establecida de la siguiente forma:
Se crea la circunscripción plurinominal electoral indígena con el objeto de garantizar la representación política de los pueblos indígenas en el congreso del estado. Dicha representación estará basada en los sistemas normativos propios de los mencionados pueblos, en concordancia con su autonomía y libre determinación (Comisión plural, 2008).

Esta propuesta está siendo aún trabajada, y las posibilidades en lo que se refiere a la exclusión de los partidos políticos plantean serias dificultades. A pesar de que los integrantes de las organizaciones tienen una afinidad por el partido de izquierda (PRD) han decidido apoyar de inicio esta alternativa como una forma de participar directamente en los espacios de decisión.

\section{Apuntes finales}

Como se observa, el camino ha sido largo, y los conflictos al interior del movimiento y las organizaciones indígenas de Michoacán han provocado división y momentos de retraimiento. No fue mi intención mostrar las diferencias que viven las organizaciones, sino dar a conocer los momentos y el conjunto común de demandas que han logrado exponer. Aunque también cabe aclarar que éstas se siguen discutiendo y que causan polémica entre los diferentes grupos de la población purépecha. Además de que una parte considerable de la población indígena apenas las conoce o tiene una opinión clara al respecto. Esto indica que las mayores discusiones se han llevado entre un grupo relativamente reducido de los pueblos indígenas de Michoacán.

La política nacional y regional ha marcado la lucha de las poblaciones indígenas en Michoacán, lejos de la idea de la no intervención del Estado, sus instituciones han adquirido mayor presencia en los contextos locales y se han vinculado con la satisfacción de demandas. En esta línea, la arena política está siendo disputada y la intervención de los partidos políticos en las comunidades indígenas es, en la actualidad, 
un factor decisivo en el posicionamiento de estos agentes. La lucha y negociación por el reconocimiento de los derechos indígenas atraviesa en Michoacán un momento de retraimiento y de limitada acción, lo que en parte ha propiciado una renovada discusión de la viabilidad de las demandas.

A estos se suma la cuestionada posición de los líderes de las organizaciones por su cercanía con el gobierno y por mantenerse en las instancias de éste. En esta línea la relación entre los líderes y organizaciones, y la población que no apoya a las organizaciones es bastante compleja, ya que las críticas hacia éstos (debido a los beneficios obtenidos en la lucha indígena, y que finalmente no han sido iguales para todos los participantes) provocan divisiones internas que el gobierno ha sabido aprovechar. El Estado ha tratado de restar legitimidad al discurso del movimiento indígena al tiempo que mantiene ocupados a los líderes en la elaboración de un borrador que no da muestras de ser presentado en el corto tiempo. Y hasta donde se percibe, como lo fue en la administración de Lázaro Cárdenas Batel, este gobierno sólo está dispuesto a reconocer derechos mínimos que no amenacen intereses de las élites políticas y económicas en el Estado.

Los discursos del Estado acerca del reconocimiento a la diferencia y la pluralidad cultural existente no han implicado mejorías, han sido parte de políticas de contención y han logrado postergar el estallido social. El más claro ejemplo fue las modificaciones hechas a la Constitución federal en 2001. Después de que la Caravana de la dignidad indígena realizada por la delegación zapatista, recorriera diferentes estados del país (incluido Michoacán es en donde se realizó el III congreso del CNI) y de que presentara al Congreso de la Unión la pertinencia de aprobar una ley de derechos y cultura indígena en consonancia con los Acuerdos de San Andrés y su versión en la COCOPA; se aprobó en abril de 2001 una modificación a la Constitución que poco reflejaba las demandas expresadas por la delegación del EZLN, y además limitaba y daba por finalizada la discusión de estas demandas. La regresión que significa dicha ley en los avances logrados a nivel regional o estatal, marcó el cierre de negociaciones entre el EZLN y el gobierno federal. Los siguientes pronunciamientos de los zapatistas llaman a las poblaciones y organizaciones indígenas a seguir en la lucha, pero hay división respecto a rechazar — como lo hacen éstos - cualquier negociación que niegue u omita la iniciativa de la COCOPA o participar y negociar en las discusiones de las reformas a las constituciones estatales, que de antemano se sabe estarían limitadas por la reforma federal (Ramírez, 2005: 10).

El Estado ha utilizado el discurso indígena, pero sin los contenidos y sentidos que el movimiento indígena le otorga. Hernández C. (2005) argumenta que aquel se ha apropiado y limitado términos como cultura y multiculturalismos, y que enarbola los discursos liberales de la igualdad como un argumento para negar los derechos políticos y culturales de los pueblos indígenas. La "nueva relación" entre éstos y el Estado se pregona a través de las (insuficientes) reformas a la Constitución (2001) y el impulso de "nuevos" programas indigenistas. El conflicto chiapaneco sigue sin solución, la militarización y formación de paramilitares continúa, y la violencia hacia las poblaciones indígenas es tolerada por los distintos niveles de gobierno. El Estado ha mostrado nuevamente su capacidad para detener las alternativas populares y ha evidenciado las divisiones internas.

No obstante lo anterior, los indígenas siguen en pie de lucha, es posible que en la actualidad no existen condiciones favorables para el movimiento indígena, $y$ se encuentre en un momento de retraimiento y en espera de un contexto político y una apertura del sistema para negociar con mayores posibilidades de éxito. A pesar de que Michoacán ha sido una arena política de negociación constante.

En esta línea, es probable que se esté a la espera de un nuevo momento de impulso en el movimiento a partir de la presentación de las modificaciones a la

Revista LiminaR. Estudios sociales y humanísticos, año 8, vol. VIII, núm. l, junio de 2010, San Cristóbal de Las Casas, Chiapas, México. ISSN: 1665-8027 
constitución local y de la propuesta de ley de derechos y cultura indígena en Michoacán. Aunque a decir verdad, se ha venido postergado con cualquier razón y es probable que se trate de un mecanismo del gobierno para mantener aquietado al movimiento y sus líderes. Por otro lado, el resto de la población que no pertenece a las organizaciones y que no mantienen simpatía por los líderes o el discurso de éstos reconoce las condiciones de desventaja en que viven, pero no está dispuesta a hacer algo más allá que su superación personal para mejorar en el entendido de que en estas organizaciones igualmente hay manipulación y corrupción.

La aprobación de una ley que goce de la anuencia de las organizaciones podría significar un gran avance en el reconocimiento de la población indígena y de sus derechos en Michoacán, lo que en este tenor no implicaría una mejoría automática de sus condiciones de vida, como fue el caso de Oaxaca. Por otro lado, si se presentara y aprobara una reforma que no goce de la participación y reconocimiento de organizaciones y líderes indígenas podría ser una clara provocación a la movilización, como ya lo fue años atrás. Lo que también podría darle de nuevo vida al movimiento y haría replantearse sus demandas y formas de hacerlas cumplir.

Finalmente, hemos visto como el contexto propició que se fortaleciera una identidad indígena, que se fue conformado en continuo diálogo con los discursos y demandas del movimiento indígena nacional y continental. Los agentes indígenas se posicionaron a través de la manifestación y pronunciamiento de demandas, aunque no siempre gozaron de todo el respaldo de la población indígena. Lograron aparecer y figurar en espacios público federales, sin embargo, la conflictividad siempre ha estado presente en el difícil reto de lograr la solidaridad y el consenso. La historicidad del movimiento indígena nos revela las relaciones de dominación y subordinación que ha establecido el Estado en su continua búsqueda de legitimidad, pero también pudimos apreciar los espacios independientes que ha logrado crear el movimiento indígena para disputar su reconocimiento y su participación en la construcción de un proyecto nacional que los incluya en igualdad de condiciones que el resto de la población; como ellos mimos afirman, han estado en este territorio y esperado casi 500 años para que sean reconocidos, entonces pueden esperar unos años más, pero ya no callados sino alzando la voz.

\section{Notas}

${ }^{1}$ Hernández H. afirma que las principales demandas del CNPI eran el respeto a la autodeterminación y a lo que configuraba su personalidad como pueblos (1988: 171).

${ }^{2}$ Hasta 1983 todos los encuentros nacionales de la CNPA se realizaron en comunidades indígenas, uno de los primeros se hizo en Santa Fe de la Laguna, Michoacán (Rubio, 1987: 34).

3 Ramírez (2005) afirma que en el periodo inicial del nuevo cardenismo (1989-1992) muchas de las comunidades indígenas fueron fundamentales para hacer posibles los triunfos electorales de este partido en municipios con alta población purépecha. Unas cuantas presidencias quedaron en manos de simpatizantes cardenistas, quienes las convirtieron en "ayuntamientos paralelos". Sin embargo, muchos de éstos fueron desalojados por las fuerzas armadas y sólo en la sierra purépecha ayuntamientos como Nahuatzen, Cherán y Paracho quedaron en manos de los inconformes hasta la siguiente elección (Ramírez, 2007: 129).

4 "Para el indio, como para el purhépecha, la tierraes la madre de la cual brota todo lo que existe, incluyendo al hombre mismo, por lo tanto el purhépecha se concibe como producto de la Madre-Tierra y al servicio de ella" (Comunidades Indígenas de Michoacán, 1995: 166).

${ }^{5}$ En el Convenio 169 de la OIT la territorialidad es definida como "Espacio para el ejercicio del derecho a la autonomía a fin de garantizar el fortalecimiento y desarrollo de los pueblos indígenas en los ámbitos políticos, económicos, sociales y culturales. La 
territorialidad se ejerce en el marco del Estado Nacional; es decir, en apego a aquellas normas que acotan este derecho por estar reservadas a la Nación de manera exclusiva, como es el caso del subsuelo" (OIT, 1992).

${ }^{6}$ La propuesta central de la ANIPA consiste en "crear otro nivel de gobierno entre el estatal y el municipal: el gobierno regional. Éste tendría jurisdicción parcial en las esferas política, administrativa, económica, social, cultural, educativa, judicial, de manejo de recursos y ambiental" (Mattiace, 2002: 251-252). No descarta la autonomía comunal, ya que ha aceptado la coexistencia de la autonomía comunitaria y municipal en lugares donde no existen condiciones para la formación de regiones autónomas.

${ }^{7}$ Esta tipología comprende: a) Municipios monolocales; b) Municipios con base en una comunidad agrariaindígena o tenencia, y sus respectivos anexos o encargaturas; c) Municipios por la agrupación de distintas comunidades indígenas; d) Municipios por reorganización de comunidades indígenas dispersas y marginales (Ramírez, 2005).

\section{Bibliografía}

Anaya Muñoz, Alejandro (2006), Autonomía indígena, gobernabilidady legitimidaden México. Lalegalización de usos y costumbres electorales en Oaxaca, México: Universidad Iberoamericana/Plaza y Valdés Editores.

Comisión plural para la propuesta de reforma constitucional para el reconocimiento de los derechos de los pueblos indígenas de Michoacán (2008), "Propuesta de reforma constitucional para el reconocimiento de los derechos de los pueblos indígenas de Michoacán (Tercer borrador para su análisis y discusión). Constitución política del estado de Michoacán de Ocampo", en Michoacán, versión electrónica.

Comunidades indígenas de Michoacán (1995), "Decreto de la Nación Purépecha”, en Relaciones, estudios de
Historia y sociedad, núm. 61/62, invierno-primavera, México: COLMICH, pp. 163-167.

Díaz-Polanco, Héctor (2001), "La autonomía indígena y la reforma constitucional en México", en Osal, El zapatismo y los derechos de los pueblos indígenas, junio, pp. 15-22.

Encinas, Alejandro R. y Fernando Rascón F. (1987), Reporte y cronología del movimiento campesino e indígena, núm. 5, enero-diciembre de 1983, México: Universidad Autónoma de Chapingo.

Hernández Hernández, Natalio (1988), "Las organizaciones indígenas: ¿Autonomía o dependencia?" en INI, Instituto Nacional Indigenista. 40 años, México: INI, pp. 166-180.

Máiz, Ramón (2004), "El indigenismo político en América Latina”, en Revista de Estudios Políticos, núm. 123, enero-marzo, pp. 129-174.

Mallon, Florencia E. (2003), Campesino y Nación. La construcción de México y Perú poscoloniales, México: El Colegio de San Luis/COLMICH/CIESAS.

Mattiace, Shannan L. (2002), "Una nueva idea de nación: autonomía indígena en México", en Shannan L. Mattiace, Rosalva A. Hernández y Jan Rus (edit.), Tierra, libertad y autonomía: impactos regionales del zapatismo en Chiapas, México: CIESAS/IWGIA, pp. 229268.

Máximo Cortés, Raúl (2003), "Orígenes y proyecto de nación P'urhépecha”, en Carlos Paredes Martínez y Marta Terán (coords.), Autoridad y gobierno indígena en Michoacán, vol. II, México: COLMICH /CIESAS/INAH/ UMSNH, pp. 581-589.

Nahmad Sittón, Salomón (2003), Fronteras étnicas. Análisis y diagnóstico de desarrollo: Proyecto nacional vs. Proyecto étnico. El caso de los ayuuk (mixes) de Oaxaca, México: CIESAS.

Organización Nación P’urhépecha (ONP), (s/f), Folleto Informativo, tríptico, ONP.

Organización Nación P'urhépecha (2000), Decálogo de los derechos fundamentales de los pueblos indígenas, Juchari Uinapikua, ONPZ, mecanografiado, p. 5. 
Organización Nación P'urhépecha (2001), Autonomía regional. Un proyecto de pervivencia para el pueblo purhépecha y para los pueblos indígenas de México, folleto, Tacuro, Municipio de Chilchota, Michoacán, p. 19.

Organización Nación P'urhépecha, Red de información indígena, en www.lantea.apc.org/rci/organinteg/ napurhe.html, recuperado enero 2004.

Organización Internacional del Trabajo, (1992), "Convenio 169", en OIT.

Paz Patiño, Sarela (2005), El estado y los indígenas en los tiempos del PAN: neoindigenismo, legalidad e identidad, en Rosalva Aída Hernández, Sarela Paz y Ma. Teresa Sierra (coords.), México: CIESAS/Plaza y Valdés, pp.357-382.

Ramírez Sevilla, Luis (2005), "Movimientos indígenas y gobiernos locales en la región purhépecha de Michoacán, México", en Seminario del proyecto Estado y Pueblos Indígenas en América Latina, COLMICH, Zamora, Michoacán, septiembre, mimeografiado, p. 33.

Representantes y Autoridades Tradicionales del Pueblo P'urhépecha, (2001), "Decreto en contra de la Ley Indígena aprobada en México", en Cemos Memoria, núm. 182, México, pp. 46-49.

Rubio, Blanca (1987), Resistencia campesina y explotación rural en México, México: Era.

Sarmiento Silva, Sergio (1996), "Movimiento indio, autonomía y agenda nacional", en Hubert C. de Gramont, (Coord.), Neoliberalismo y organización social en el campo mexicano, México: UNAM/Plaza y Valdés Editores, pp. 355-395.

Sarmiento Silva, Sergio (2001), "El movimiento indio mexicano y la reforma del Estado", en Cuadernos del Sur, Oaxaca: INAH/IIS-UABJO, pp. 65-96.

Stavenhagen, Rodolfo (1988), Derecho indígena y derechos humanos en América Latina, México: COLMICH /IIDH.

Victoriano Mateo, Alfredo (1997), Juchari Juramukua (Nuestra Autonomía), cuadernillo, ONP, Cherán, Mich., $21 \mathrm{pp}$.

Yasumura, Naoki (2003), "Polifonía en la construcción de lo purhépecha. Un caso de la política de identidad", en Carlos Paredes Martínez y Marta Terán (coords.), Autoridad y gobierno indígena en Michoacán, vol. II, México: COLMICH /CIESAS/INAH/ UMSNH, pp. 643-673.

Zárate Hernández, José Eduardo (1999), “La reconstrucción de la nación purhépecha y el proceso de autonomía en Michoacán, México", en Willem Assies, Gemma van der Haar y André Hoekema, (Edit.), El reto de la diversidad. Pueblos indígenas y reforma del estado en América Latina, México: COLMICH, pp. 245-267.

\section{Entrevista}

Entrevista a N. C., Tacuro, municipio Chilchota, Michoacán., 2005. 